Please do not remove this page

RMIT

UNIVERSITY

\title{
'Going green'?: The limitations of behaviour change programmes as a policy response to escalating resource consumption
}

Moloney, Susie; Strengers, Yolande

https://researchrepository.rmit.edu.au/esploro/outputs/9921859732701341/filesAndLinks?institution=61RMIT_INST\&index=null

Moloney, S., \& Strengers, Y. (2014). "Going green"?: The limitations of behaviour change programmes as a policy response to escalating resource consumption. Environmental Policy and Governance, 24(2), 94-107. https://doi.org/10.1002/eet.1642

Document Version: Accepted Manuscript

Published Version: https://doi.org/10.1002/eet.1642

Repository homepage: https://researchrepository.rmit.edu.au

(c) 2014 John Wiley and Sons, Ltd and ERP Environment

Downloaded On 2023/04/26 21:54:02 +1000 
Thank you for downloading this document from the RMIT Research Repository.

The RMIT Research Repository is an open access database showcasing the research outputs of RMIT University researchers.

RMIT Research Repository: http://researchbank.rmit.edu.au/

\section{Citation:}

Moloney, S and Strengers, Y 2014, "Going green'?: The limitations of behaviour change programmes as a policy response to escalating resource consumption', Environmental Policy and Governance, vol. 24, no. 2, pp. 94-107.

See this record in the RMIT Research Repository at:

https://researchbank.rmit.edu.au/view/rmit:24420

Version: Accepted Manuscript

Copyright Statement: (C) 2014 John Wiley and Sons, Ltd and ERP Environment

Link to Published Version:

http://dx.doi.org/10.1002/eet.1642 
Cite as: Moloney, S. and Strengers, Y. (2014) 'Going Green'?: the limitations of behaviour change programs as a policy response to escalating resource consumption, Environmental Policy and Governance, 24, 94-107.

\title{
'Going Green'?: the limitations of behaviour change programs as a policy response to escalating resource consumption
}

\begin{abstract}
The narrow preoccupation with targeting individuals to encourage the uptake of 'easy' actions represents a limited approach to redressing escalating resource consumption associated with our daily lives. This paper contributes to a growing body of literature highlighting the limitations of behaviour change and the emergence of a social practice framing as an alternative. Drawing on insights from interviews with Australian households and workshops with behaviour change practitioners, this paper demonstrates how the 'Going Green' discourse, which is focused on a set of 'easy' actions targeting individuals, overlooks the vast majority of consumption implicated in everyday social practices, including eating, bathing and entertaining. This leaves unchallenged the many and complex ways our lives are becoming more resource intensive. We argue for an ontological framing of social change underpinned by theories of social practices. As an alternative to behaviour change, this approach examines how and why our consumption practices are changing and illustrates why positioning environmental responsibility at the level of the individual is inadequate. We argue that confronting the escalating rate of resource consumption in our daily lives will necessitate changes at a range of scales and across policy spheres which calls for greater responsibility, in particular from government, in leading and enabling those changes.
\end{abstract}

Keywords: behaviour change, environmental responsibility, sustainable consumption, social practices. 


\section{Introduction}

Over the last few decades there has been an explosion of environmental information and education programs in Australia and internationally aimed at changing individual behaviours (for reviews see, Moloney et al. 2010; Southerton et al. 2011). Many of these initiatives reflect a growing and pervasive discourse premised on the notion that in order to achieve sustainable consumption we must target and change consumer behaviours and lifestyle choices, while simultaneously improving efficiency and productivity (Jackson, T. 2006). This discourse, which we call 'Going Green', is concerned with changing individuals' attitudes to encourage the uptake of small actions, techno-efficiency measures and 'green' product choices in and around the home. The Going Green discourse sits within a broader political framing of governance responses to environmental problems dominated by 'eco-modernizers' and neo-liberal economists (Hopwood et al. 2005). It situates the story of a fragile and vulnerable planet as tangible and localised-something which can be 'worked on' in the context of the home through participation in easy actions (Macnaghten 2003). We argue that this discourse, and its resulting policies and programs, has a limited capacity to deliver the types of consumption changes needed to reduce environmental impacts on the scale recommended by leading international scientists (e.g. IPCC 2007).

There is now a growing body of international literature highlighting the limitations of behaviour change (Barnett 2010; Southerton et al 2011; Fudge and Peters 2011), particularly its failure to achieve significant environmental and social change (Burgess et al. 2003). According to Burgess et al. (2003, p. 270) "the remarkably rapid increase in public awareness of environmental issues and embracing of pro-environmental attitudes is coupled with virtually no substantive changes in behaviours at all". In recent years, researchers from a number of disciplines have been reviving and extending a longer theoretical tradition of social practice theories to explain and understand processes of social change in relation to environmental problems (Barr et al. 2011; Christensen et al. 2007; Everts et al. 2011; GramHanssen 2009, 2011; Halkier et al. 2011; Hargreaves 2011; Røpke 2009; Shove 2010; Shove, E 2010; Spaargaren, Gert 2011; Warde 2005). This body of work is offering useful conceptual tools for understanding the so called 'value-action' gap (the gap between values and actions) and helps to explain why pro-environmental attitudes do not necessarily lead to changes in behaviour. 
This paper contributes to this body of work by developing understandings of social practice as an alternative conceptual approach to devising programs and strategies that aim to reduce resource consumption in everyday life. We draw on insights from our empirical research with Australian householders and practitioners involved in behaviour change programs to highlight the constraints and limitations of current approaches to social change, and to illustrate how theories of social practice can help reconceptualise so-called 'externalities' as elements and processes of practices.

We recognize that the Going Green discourse and the programs it perpetuates play a role in achieving efficiency gains and resource savings by individually recruiting environmentallymotivated people. However, in framing behaviour around 'small' and 'big' environmental actions, and in focusing primarily on resources and their environmental impacts, this discourse largely overlooks the social practices in which all consumption is implicated (Warde 2005). In the context of the home, these practices include laundering, food preparation, entertaining, gardening, bathing, heating and cooling practices, as well as how we get around. These practices shape and are shaped by the things we consume outside the home such as the food we buy, and the clothes, appliances and transport we use

Deliberately attempting to transform practices which consume energy and water requires a broader understanding of how and why they are changing, political recognition that change is required, and acknowledgement that practices have 'emergent and uncontrollable trajectories' (Shove, E \& Walker 2010, p. 475) that cannot necessarily be directly or deliberately manipulated. This requires a new ontological framing of change-one which looks beyond the agency of individual consumers and designated 'change agents' (such as behaviour change practitioners), to actively engage in the composition and reproduction of 'normal' everyday life (Hargreaves 2011; Spaargaren, G. \& Oosterveer 2010; Strengers 2012). By recasting behaviour change within this alternative paradigm, new roles and opportunities emerge for how we might address the sustainability challenge.

This paper first discusses how the discourse of Going Green has emerged as part of a broader political response to environmental governance framed within a neo-liberal agenda. We illustrate how, despite good intentions, many behaviour change programs and initiatives are inherently limited in framing efforts to achieve change around individual actions and outcomes. Using the example of the Australian Conservation Foundation's (ACF) 
GreenHome Program, we illustrate how the discourse of Going Green is 'lived out' by 19 households participating in the program. We also discuss data from three workshops involving 22 behaviour change practitioners included in a broad review of 100 behaviour change programs in Australia (Moloney et al. 2010). Drawing on theories of social practices (Reckwitz 2002b; Warde 2005), we demonstrate the limitations of Going Green, and highlight the ways in which consumption becomes normalized and transformed through participation in social practices. We conclude by arguing that moving beyond the current preoccupation with Going Green and the behaviour change programs it promulgates requires a political and practical reorientation that critically engages with and seeks to transform how we live.

\section{The Politics of Going Green}

Over recent decades, environmental governance and goals have focused around two key ideas: first, that strategies for change must bear little or no economic cost or must not place limits on development; and second, that the role of voluntarism and information provision is crucial to achieving environmental change (Hobson, K. 2006). These responses to environmental problems are consistent with the ecological modernization paradigm, where efficiency measures take precedence and "economic growth and resolution of environmental problems can, in principle, be reconciled" (Christoff 1996, p. 482). According to Hajer (1995, p. 32), the problem with ecological modernization is that it "does not address the systematic features of capitalism that make the system inherently wasteful and unmanageable". Hajer highlights an important contradiction inherent in this paradigm: consumption is framed both as an environmental problem and as necessary fuel for the capitalist engine. Consequently, current responses to environmental problems attempt to 'manage' the tension between capitalism and consumption so that our impacts are minimized while not challenging or altering the rates of consumption and economic growth (Luke 2005). For example, Hopwood et al. (2005, p. 40) argue that the influential but ambiguous Brundtland report's framing of sustainable development has effectively allowed governments and businesses to be "in favour of sustainability without any fundamental challenge to their present course". In mapping the broad field of interpretations or views on sustainable development, they identify three categories - (i) status quo, (ii) reform, and (iii) transformation - under which they group a wide range of responses to environmental problems (Hopwood et al. 2005). 
The sustainable development discourse is dominated by those operating within the 'status quo', which include neo-liberal economists and 'eco-modernizers', who present no fundamental challenge to economic growth or 'business as usual'. Hopwood et al. (2005:48) argue that if we are to move towards a "sustainable livelihood for all", then maintaining the status quo is not an option, instead what is needed is transformation. Given the significant challenges this presents, they propose that a reform agenda be adopted, which amongst other things would raise the prospect of 'self- reform' across governments and big business "to challenge the powerful vested interests that act in ways contrary to sustainable development" (Hopwood et al. 2005, pp. 48-9).

The dominance of the 'status quo' is evident in how governance responses are framed to target individual consumption and its impacts, particularly in the highest consuming developed nations (OECD 2002). Hobson (2002, p. 100) explains how the 'citizen consumer' fits within the dominant ideology of neo-liberalism (and within the broader goals of capitalism) where the burden of environmental problems is attributed to the 'choices and actions' of the consumer. Rather than emphasizing reducing consumption, the focus has been on improving the efficiency of products and services consumed. The preoccupation with targeting consumers to 'do their bit' has been described in political economy terms as the "privatisation and individualisation of responsibility for environmental problems" which "shifts blame from state elites and powerful producer groups to amorphous culprits like 'human nature' or 'all of us"” (Maniates 2002, p. 57). According to Marres (2011), this transference of responsibility engenders at least two forms of public participation in global environmental concerns, one where actions are made so easy they could be described as a 'change of no change', such as changing a light bulb, and another where local participation is positioned as 'hard work' which actively seeks to produce material effects such as an ecohouse or solar panel array. Actions are reduced to 'small' and 'big', 'easy' and 'difficult', with information and education (from government) and access to the right technological equipment positioned as the pathway to being a good environmental citizen.

The emergent policy and program focus on small and big individual actions generates two critical problems for achieving significant social and environmental change. First, it divests governments of responsibility for environmental change aside from educating, informing and supporting its citizens, instead relying on markets and individual action (Hinchliffe 1996); and, second, it results in a narrowly defined scope for how to affect change, and who should 
make change happen. Broadly identified, these concerns cut to the core of the limitations of the Going Green discourse, and the contention for an alternative political framing of social change.

\section{The Programs of Going Green}

We use 'Going Green' to encapsulate an expanding discourse which recommends and promotes different ways of being and becoming 'green' by encouraging voluntarism and providing information and education. It is most clearly evidenced by an explosion of books with titles like Greeniology (Ha 2007), Easy Green Living (Loux 2008) and The Green Book (Rogers \& Kostigen 2007), as well as websites promoting GreenHome and GreenSmart programs (ACF 2004; HIA 2009). There is a strong emphasis on Do It Yourself (DIY) retrofits and actions, promoted through a range of programs, workshops, forums, and campaigns as is evident in Australia, the UK and other developed nations (see Jackson, Tim 2005; Moloney et al. 2010; Shipworth 2000 for reviews).

A review of over 100 Australian behaviour change programs illustrates how this discourse has become all-pervasive, with funding coming primarily through state and local governments as well as non-government organizations (Moloney et al. 2010). Easily achievable actions are promoted, including reducing shower time, installing efficient showerheads and light globes, turning off lights when not in use, turning off stand-by power, choosing food with less packaging, and using cold water for laundering (see, for example, SV 2009b). Alongside encouraging the uptake of these small pro-environmental behaviours, there are a set of 'bigger' actions, such as installing water tanks, solar panels or insulation, purchasing more efficient appliances, and ensuring the sustainable design and construction of buildings or home renovations.

Across the breadth of typical behaviour change programs and campaigns, the pervasive Going Green discourse frames social and environmental change as a largely individuallydetermined phenomenon, drawing on economic 'rational choice' and/or psychological Attitudes, Behaviour, Choice (ABC) understandings of consumption (critiqued by Shove 2010). Within the ABC model, behaviour changes when individuals adopt pro-environmental attitudes (A) and behaviours (B), and when they are encouraged to make better consumption choices (C). As rational actors, individuals are positioned as consumers (of energy and water) who use fewer resources if offered the 'right' incentives and information. This perspective 
has gained significant momentum in recent years through developments in behavioural economics, particularly the concepts of Nudge and Libertarian Paternalism which implicitly underpins many behaviour change programs (Thaler \& Sunstein 2008). Thaler and Sunstein (2008) explain how these terms are used to encapsulate strategies that make it easy for people to make the 'right' choices, whilst still exercising their own freedom. This encapsulates strategies which aim to 'nudge' householders in the right direction.

This discourse permeates the political arena, generating funding and research opportunities that uphold and reinforce the status quo (Shove 2010), even when it is acknowledged as being inadequate. For example, a report produced for the Victorian State Government states that "attitudes may not always translate into behaviour" and that "behaviour changes takes place within the context of broader social circumstances" (UrbanTrans 2008, p. 11). However, there is little reflection on these 'circumstances' and what they mean for how behaviours can or might change, and a lack of critical engagement with the role of behaviour change initiatives. Indicating the report authors' commitment to the Going Green discourse, this document presents findings on how the Victorian Government can increase funding to, and better support, behaviour change programs, including a recommendation to develop research "into links between attitudes and behaviours" (UrbanTrans 2008, p. 24). Another state government report questions the reliance on individual agency for change by providing evidence that while more people feel pressure to do something about the environment, there are also an increasing number who feel "climate change effects are too far in the future to really worry them ... suggesting the community has lost some confidence in being able to personally influence climate change" (SV 2009a, p. xv). Similarly, this report challenges the legitimacy of using behaviour change programs as an adequate governance response to achieve social change and raises important questions regarding the role of Government in acting to better enable and support people to live more sustainably.

\section{Recasting what it means to Go Green: theories of social practices}

Shove (2010, p. 2) contends that 'framing 'the problem' of climate change as a problem of human behaviour marginalizes and in many ways excludes serious engagement with other possible analyses including those grounded in social theories of practice and transition". Programs which target a few key actions in the home are incapable of fundamentally challenging the status quo, because of what they ignore and exclude from their purview. In particular, the Going Green discourse spectacularly ignores how and why we do what we do, 
and how practices and routines come to be 'normal'. We are not suggesting that such issues need to be incorporated into the existing discourse as additional 'factors' to consider, but rather that an alternative discourse is required, and therefore, a different political reality or 'ontological politics' (Hawkins \& Race 2011; Mol 1999). We take our cue from Elizabeth Shove (2010), who has previously argued for the much greater role of social theories in the framing of policy problems that extend beyond the $\mathrm{ABC}$.

Instead of seeing the world as being populated by rational and autonomous individuals, we draw on theories of social practices to illustrate how "the social world is first and foremost populated by diverse social practices which are carried out by agents" (Reckwitz 2002b, p. 256). In the words of Anthony Giddens, the basic domain of enquiry "is neither the experience of the individual actor, nor the existence of any societal totality, but social practices ordered across space and time" (Giddens 1984, p. 2). Individuals are repositioned as 'carriers' of practices: they embody routines, perform practices and innovate through doing, but they are no longer considered the primary unit of enquiry or focus of change (Pantzar \& Shove 2010; Reckwitz 2002b).

A social practice can be identified as "an interwoven activity in a social domain" (Schatzki 1997, p. 285). It is quite different from behaviour, which while shared, is ultimately the responsibility and product of each individual. Rather than being the outcome of a series of attitudes, values or opinions, a social practice can be understood as constituted of several socially shared elements, including materials such as infrastructures and technologies, meanings and understandings about what we ought to do, and embodied skills and practical knowledge about how to do it. Practices are reproduced in everyday life in the form of the routines, habits, or daily activities which make sense for us to do (Schatzki 2002). They are often considered mundane or taken for granted, such as how and why we shower, bathe, eat, heat, cool or clean, yet they are the basis through which all consumption is implicated (Warde 2005). Individuals then, do not consume resources, but participate in social practices which are mediated by availability and access to resources. Practices are continuing to shift and change, often in more resource-intensive and environmentally-damaging directions, making them essential in discussions of sustainability and consumption. 
Shove (2010, p. 6; refers to Rip 2006: 87) describes how this political reorientation redefines sustainability problems, opportunities for 'transition', and the roles of various actors committed to affecting change:

This way of thinking suggests that transitions towards sustainability do not depend on policy makers persuading individuals to make sacrifices, specified with reference to taken for granted benchmarks of normal non sacrifice; or on increasing the efficiency with which current standards are met. Instead, relevant societal innovation is that in which contemporary 'rules of the game' are eroded; in which the status quo is called into question and in which more sustainable regimes of technologies, routines, forms of know-how, conventions, markets and expectations take hold across all domains of daily life. These are not processes over which any one set of actors has control.

Consequently, the scope and trajectories for change are redefined. Common understandings circulate and spread through practices, 'things' and infrastructures act as mediating and reorienting devices, institutional and political laws and recommendations set courses and trajectories for change, and practical experiences 'lock in' (and provide ways out of) particular ways of doing things, all of which can shift a practice's composition and reproduction (Reckwitz 2002a; Shove, E \& Pantzar 2005).

\section{The limits to Going Green}

\section{The participants and the practitioners}

Our research is premised on the assumption that the scale of change required to meet the environmental and social challenges of our time is significant and far-reaching. We use the ACF GreenHome ${ }^{1}$ program to highlight the limitations of the Going Green discourse in achieving the societal transformation necessary to address environmental challenges such as climate change. We do not present the full details of our empirical analysis of this program: details of this can be found elsewhere (Strengers 2009). Rather, we use this material to

\footnotetext{
${ }^{1}$ Our analysis refers specifically to the 2007 version of the ACF GreenHome Program. We acknowledge that ACF is continually changing and updating the program. We also acknowledge that ACF is engaged in significant work beyond this program, including political lobbying and policy engagement).
} 
conceptually critique and reframe behaviour change programs from a social practice perspective.

This free workshop-based program was designed to encourage and inspire people to green their homes, and features remarkably similar information and objectives to Helping the Environment Begins at Home, the more than decade-old UK Government campaign critiqued by Steven Hinchliffe (1996). ACF is a not-for-profit environmental organisation largely funded by individual membership and donations. In Victoria, the program was initially supported by the Victorian Government's Department of Sustainability and Environment (Goldsmith \& Villadsen). The program typically involved a number of mid-week evening community workshops at local town halls or community venues focusing on what individuals can do to reduce their household energy, water and waste. Participants received a GreenHome Guide (ACF 2006) and some technologies to assist them in greening their homes, such as a water-efficient showerhead, flow restrictors for the toilet and taps, energyefficient light globes, and a shower timer.

This paper draws empirical insights from qualitative interviews with 19 households $^{2}$ which were conducted during 2007 on the Mornington Peninsula in the Australian state of Victoria (Strengers 2009). Throughout this paper, households are referred to anonymously by a number (H1-H19). Interviews were semi-structured and conversational in format although a series of themes and questions were covered pertaining to practices which consume the majority of energy and water in Australian homes (bathing, laundering, heating, cooling and toilet flushing) ${ }^{3}$. Each interview was followed by a household tour, where householders were asked to show the researcher any technologies, infrastructures or 'things' that contributed to the comfort and cleanliness of the home ${ }^{4}$.

\footnotetext{
${ }^{2}$ Interviews were conducted with 19 households (37 individuals) participating in the Dromana (10 households) and Frankston (9 households) GreenHome programs (Strengers 2009). Household participants were recruited for this research during their attendance at GreenHome workshops, where they were asked to volunteer. Interviews were conducted at the household's residence, and included as many members of each household as possible (including children). A broad range of household types were self-selected for this study.

${ }^{3}$ Comfort practices (heating and cooling) account for almost half of household energy consumption (DEWHA 2008), whereas indoor cleanliness practices, particularly bathing, laundering and toilet flushing, account for more than half of household water consumption (Davidson 2008).
}

\footnotetext{
${ }^{4}$ The whole visit to the household, encompassing an interview and the tour, took approximately one hour. The entire visit was voice-recorded and transcripts were either fully or partially transcribed. All data were imported into NVivo software for coding and thematic analysis.
} 
Additionally, the paper also draws on insights from workshops with behaviour change practitioners involved in a range of programs, including ACF GreenHome. Practitioners were recruited for this research through their involvement in a three year research project (titled 'Carbon Neutral Communities: Making the Transition'), which involved a review of 100 Australian behaviour change programs (Moloney et al 2010). Three workshops were held with a total of 22 practitioners, who were asked to reflect on their programs and discuss an alternative 'social practices' approach to understanding household consumption. Practitioner comments from these three workshops are referred to anonymously throughout this paper by workshop number (W1-3). In the discussion that follows, we use these two datasets to illustrate the limitations of the Going Green discourse, and to identify the consumption attributed to social practices which is not addressed in the dominant framing of behaviour change.

\section{The small and big acts of going green}

Householders identified a number of small Going Green actions they undertook to reduce their environmental impact, either prior to or as a result of the GreenHome program (see Table 1). This finding supports evaluation surveys which show that "participants are making small changes and that they want to move to taking bigger actions" (ACF 2009, p. 10). While it is difficult to assess the resource savings achieved as a result of these actions there is a stated expectation in the evaluation report that the program would lead to "green solutions and behaviours becoming the social norm or part of everyday life" (ACF 2009, p. 16). The small actions adopted are mostly efficiency improvements and are likely to have little impact or bearing on the practices they are implicated in. For example, using a bucket in the shower, or changing to a water-efficient showerhead, does not fundamentally change the meanings or understandings (smell, hygiene and presentability), materials (the shower itself) or skills (about how to clean the body) associated with the practice of showering. While this does not dismiss the energy and water savings householders achieve through these small actions, it does illustrate how small efficiency changes can exist independently of, or not significantly impact on, the routines, meanings and conventions of showering.

See Table 1: Examples of small green actions 
In contrast to the habitual and taken for granted practice of showering, these green actions have a strong environmental and consumption focus and fundamentally do not seek to challenge 'normality'. Consistent with Going Green, they require conscious reflection from householders, not to identify how a practice like showering can be fundamentally changed, but to establish how the consumption associated with them can be minimized or saved through small easy actions and/or technological retrofits. In focusing on consciously shaving and cutting back their consumption, householders described how green actions were viewed as an "inconvenience" (H5), "time-consuming" (H10), or as an extra thing to think about that exists on top of or somehow separate to 'normal' social practices. This was supported by a number of program practitioners who identified that some participants consider the adoption of green actions to mean a "more difficult lifestyle" and for some, adopting one action is considered adequate (W1).

These findings highlight our two critical concerns with Going Green; (i) that only those householders who strongly identify with the discourse will be attracted to this conscious process of environmental decision-making; and (ii), that by focusing on the uptake of a set of distinctive 'green' actions, rather than practices more broadly, the vast majority of consumption implicated in normal everyday life will be overlooked. The first of these concerns is clearly illustrated through the type of householders participating in the GreenHome program, who were already highly engaged with Going Green. For example, many participants described how they enjoyed the way the GreenHome program reinforced their green actions and identity:

I really enjoyed being with likeminded active people. It reinstates your beliefs (H9)

It's given me enthusiasm. I love it. I just love getting together with likeminded people who are proactive rather than sitting there winging about stuff (H10).

However, others were disheartened by the lack of new information, indicating they were already well-versed in the recommendations of Going Green: 
It didn't tell me anything I didn't know which was a tiny bit annoying I suppose (H13).

A lot of the everyday stuff I found I was already doing (H19).

The highly motivated group of 'green' individuals attracted to Going Green indicates its inherently limited appeal: it attracts recruits interested in engaging in conscious environmental decision-making and/or subscribing to a 'green' identity. This was also acknowledged by a practitioner:

There are a wide range of people who do not associate with what it means to 'be green'. Many people don't want to be seen as 'greenies'. A perception persists that life is less pleasant and fun if you are environmental (W1).

The second concern of the Going Green discourse, namely that it obscures social practices considered normal or necessary, is illustrated by householders who commented that they were already doing everything they could to be sustainable, describing themselves as "not big consumers" (H5), "pretty frugal” (H7) or "not [using] that much anyway" (H8):

I haven't been looking at the energy. There is nothing I can do about it really. All I can do is turn off the lights and I have no control over the other three [people in the house] (H13).

Instead, when talking about future changes they could make, householders discussed "big ticket items" recommended by Going Green, which they were often unable to afford. This finding is reiterated in other reports including an evaluation report for a Victorian community based behaviour change program, Castlemaine 500 (CVGA 2008), as well as a Victorian Government 'Green Light' report on attitudes and behaviours (SV 2009a) The sorts of 'bigger' changes many would like to change (but few can or will) include installing water and energy supply systems and purchasing energy and water-efficient appliances as summarised in Table 2. These actions were discussed in terms of being an 'investment' in sustainability. They are consistent with the narrow framing of individual environmental responsibility where the emphasis is on the role of the consumer to bear the cost of investing in a more efficient or less environmentally harmful technology. For example, a new washing machine was deemed 
necessary to further reduce the energy and water associated with laundry, and renovation was required to improve the efficiency of a building.

\section{See Table 2: Examples of 'big ticket' green actions}

The complicated terrain of 'normal' social practices, which are not really addressed through small and big actions, remain disassociated from the Going Green discourse. This disconnection was illustrated by householders who were sometimes unable to relate the practice-themed discussion led by the researcher to their consumption. For example, at the conclusion of one interview a householder commented as follows: "I thought you were going to enquire more about the electricity"' (H12). Importantly, this householder didn't identify that the questions asked about the most energy-consuming practices in the household (e.g. heating, cooling, bathing and laundering) were connected to their energy usage, because they didn't refer specifically to the small and big acts of Going Green (such as turning off lights or installing solar panels), or to 'energy' terms such as kilowatt hours and greenhouse gas emissions Instead, householders often wanted to discuss their small or big actions, such as light bulbs and lighting habits, even though interviewees were never explicitly asked about lighting during the interview, a finding discussed elsewhere (Gram-Hanssen 2008; Strengers 2011). A practitioner acknowledged the political status quo underpinning these responses, highlighting how programs focus on encouraging people to switch off standby power because there are energy savings to be achieved, and because adopting this habit "doesn't really affect lifestyle" (W1). Thus, lighting is what Marres (2011, p. 523) describes as a "change of no change' - one which disrupts neither the practices of governments or householders, whilst simultaneously facilitating '(a) easy participation, (b) minimum investment and (c) little to no disruption to existing infrastructure'.

These findings reveal how the Going Green discourse can both expose and hide particular forms of consumption (Shove, E 1997). In the Going Green discourse, what 'counts' as consumption are the bits of energy and water that can be saved by introducing new habits (switch off lights) or techno-efficiency measures (use efficient lights), without fundamentally challenging or changing existing social practices (Strengers 2011). In contrast, the consumption implicated in 'normal' practices remains hidden and reinforced as essential, non-negotiable and non-discretionary activity. In one case, a householder was beginning to recognise these distinctions: 
I have been thinking about change. Are we trying to have the same living standards and use less things or are we actually trying to change the way we live? Now it was a bit of a revelation when I had that thought, and I think for me I was trying to keep living in the same standard without actually changing the way I was living. ... Well I think it's very marginal how much you can actually save water or power if you don't actually change the way you live. ... I haven't come to the conclusion on which way I want to go. It's one thing to say it and another thing to live it (H13).

The danger this householder highlights is that the ability to achieve change is limited if you are not, as they put it, "actually [changing] the way you live" (H13). This change is further limited by the decision being framed as an individual lifestyle choice, rather than a process of socio-technical change. The onus is on them, as an individual consumer, to live differently. There is also an additional concern not identified by this householder, which is that social practices are subject to constant forms of negotiation and debate which have important consumption implications. Bathing practices, for example, have a long history of change resulting from particular ideologies and norms of cleanliness, presentability, hygiene, body odour and smell; and changes to infrastructures such as showers and piped water, which are constantly manipulated by advertisers, marketers and other influential groups (Ashenburg 2007; Shove, E 2003). This raises further questions about the capacity of programs such as GreenHome to affect long-lasting and wide-reaching change.

Behaviour change practitioners acknowledge these limitations, but frame them within existing political understandings of social action and change. For example, in a practitioner workshop, some were concerned that addressing 'systemic barriers', or 'social norms' was beyond their capacity - seeing these as additional factors, barriers or issues to be addressed, rather than as the building blocks of social practices. Some highlighted that the nature of program delivery means that their organisations do not have enough time to understand complexities such as social norms, as "they normally don't get funded to do a preinvestigation" (W1). Others went further saying that if behaviour change programs focused on challenging consumer capitalist society, change would be too slow or politically threatening (W2). There is a clear tension then about what behaviour change practitioners can 
realistically hope to achieve when they are situated within the Going Green discourse. We return to this issue later.

\section{Challenging the status quo}

Beyond the identifiable set of green easy actions and longer-term big ticket items, householders discussed the murkier realm of normal everyday life, where the majority of taken for granted consumption occurs in the form of mundane and routinized social practices. They were asked, through the interview, to reflect on what they did and why they did it, often citing their practical or historical experiences as reasons for their current practices ("we were brought up that way" (H12)), or a "certain standard" (H3) they had inherited from their parents, as reasons and motivations for their non-negotiable practices. Viewed from the theoretical standpoint of social practices, such explanations allude to the importance of practical experience and accumulated social know-how (Reckwitz 2002b), and to particular configurations of elements (understandings, infrastructures and skills) that make any given practice the sensible and logical thing to do.

As knowledgeable, reflexive and competent 'carriers' of social practices, householders reflected on the various processes of stasis and flux that practices were subjected to as they were challenged, manipulated and reconfigured in ways that extended beyond individual choices and decisions. In the following examples, householders' understandings of normal ways to wash clothes were challenged by peer conversations and observations, in some cases leading to recruitment into new practices or changes to existing ones:

Just looking at other people's practices I could see that there were better ways to do the washing and things like that than just wasting it (H6).

I used to wash in warm water thinking well at least a bit of warmth gets the dirt out and a friend said that she washed in cold water all the time and I tried it and it was fine, so I just use cold water now (H19).

In other cases, regulations such as water restrictions, which prohibit certain outdoor practices, but not those involving indoor water use, subtly reinforced 'normal' practices (such as the daily shower), or legitimised their status as essential: 
They're not necessary things [referring to outdoor water practices], whereas having a shower is $(\mathrm{H} 1)$.

Because of the focus on conscious and rational decision-making, Going Green masks these inter-relationships between policy and definitions of 'normality'. Similarly, the lack of political discourse on those practices considered necessary or non-negotiable reinforces their status as 'private', 'personal' or 'confidential', potentially limiting opportunities for innovation and change towards a sustainability agenda. In contrast, normal practices are subject to forms of manipulation outside the Going Green discourse, within the broader agenda of capitalism, which is concerned with generating needs and wants in order to sell new or more products and services. Maller et al. (2011) come to a similar conclusion in their study of green home renovators, showing how householders focus on 'big ticket items' and 'low hanging fruit' during the home improvement process, while simultaneously increasing the size of their home or adopting a thermally-inefficient open-plan design.

Illustrating these dynamics, some householders discussed how understandings of 'normal' social practices were being deliberately challenged and manipulated through advertising and marketing campaigns, which were thought to directly compete with the Going Green discourse:

[Cleaning companies] create these expectations. It's not enough to have your bench clean, you've got to have it anti-bacterial and anti-microbialized and God-knows-what-else! And it's just like, that's the next bar that's getting raised now (H19).

Such campaigns directly target the elements of practices, promoting new forms of competence and skill, attempting to establish new understandings about what is 'right' and acceptable, and encouraging householders to purchase and use new things that require and reproduce these meanings and skills. This stands in contrast to Going Green's “environmental focus", where "fundamental issues about the specification of demand fall (or are pushed) beyond the bounds of normal debate" (Shove, E 2003, p. 6; emphasis in original).

Importantly, processes of practice persistence and change operate outside, and are obscured by the Going Green discourse. By this we mean that the discourse does not directly engage 
with, question or challenge what people think is normal and necessary, or why they might think it is so. Overlooking this rather vast and movable understanding of normal everyday life is problematic if we intend to achieve long-lasting, far-reaching and significant environmental change.

\section{Beyond Going Green}

Behaviour change programs have a limited capacity to affect change, first because of their limited appeal, and second, because of the types of changes they attend to and what is left out. Even within their current scope, achieving success is difficult, ensuring the long-term adoption of short-term actions beyond the life of a program is not guaranteed (ACF 2009), and encouraging 'bigger' actions is met by a range of challenges including cost, housing tenure and so on. Attempts to broaden the range of actions targeted will not overcome the inherently limiting primacy placed on individual responsibility and choice.

Behaviour change practitioners, many of whom are well aware of these limitations, will continue to have a limited capacity to challenge the status quo if the focus remains on individual behavior change. Alternative approaches which challenge the more systemic elements shaping practices certainly presents a more complex and difficult task.For example, one practitioner asked a particularly poignant question in a workshop: "How do we challenge a consumer society without being politically threatening?", with someone adding, "We have to work within the system we have" (W2). Hence, while practitioners acknowledge external 'factors' and 'forces' contradicting or contravening their efforts, such issues are often positioned outside of their control and role as 'change agents', and outside the discourse of Going Green. While we acknowledge the political constraints within which practitioners are operating we argue that there are opportunities to change the way problems are framed so that solutions and programs are targeted at practice change rather than individual change.

Our aim has been to illustrate how theories of social practices can help to reconceptualise socalled 'externalities' as elements and processes of practices. When we start with practices (rather than people) as the primary unit of enquiry and change, we are encouraged to reconsider the role and function of the behaviour change practitioner or 'change agent', rather than overlook 'factors' or 'issues' deemed beyond their control. While we fully appreciate the fundamental challenge this presents to practitioners, we argue that by continuing with an agenda that does not challenge the status quo, and by continuing to 'practice' behaviour 
change, valuable energy and efforts to affect change are potentially wasted, and the Going Green discourse is reinforced, reproduced and perpetuated.

An additional danger of this approach is that new resource-intensive practices may emerge that are not deemed part of the small suite of small or big actions necessary to 'go green'. New ICTs are posing particular problems in this regard (Røpke et al. 2010). For example, the consumer electronics sector, encompassing entertainment technologies, computers and gadgets, is now one of the fastest growing areas of electricity consumption in the home (EST 2007). By focusing householders on 'easy' actions like ensuring unused electronic devices are on standby power, we potentially shift attention away from the growing number of devices in the home (Gram-Hanssen 2009).

In addressing both the existing and possible future consumption associated with social practices, behaviour change, as a concept and an approach, needs to be recast as something else entirely. In Shove's (2011, p. 264; emphasis in original) view, the aim is not to view social practice theories as a tool for better solving or responding to the limited set of policy problems that currently attract attention (such as how to change people's behaviour), but to "generate different definitions of the problem".

One place to begin is for behaviour change practitioners and their funders to take a more reflexive approach to their own practice of 'doing' behaviour change. Behaviour change practitioners can then seek to innovate from within their roles. This might involve developing lines of enquiry and methods of engagement which legitimately explore how and why social practices are constituted and enacted in everyday life. Recast in this light, practitioners may act as agitators and lobbyists, highlighting the interconnections between practice elements, drawing on their knowledge and work with households and communities. Practitioners therefore become less concerned with effective persuasion and communication techniques and act rather as conduits or 'intermediaries' (Hodson \& Marvin 2010) between the practices they seek to change and the issues mitigating or facilitating those changes. In this capacity practitioners seek to establish or integrate new elements of practices, or challenge existing taken for granted practices. While perhaps a daunting task, this means that a program for change is emergent rather than pre-determined in the form of a 'toolkit'. By starting with practices and the desire to better understand their trajectories in terms of resource consumption it is possible to open up opportunities to challenge 'normality' and work towards alternatives. Talking about what is normal and why it is so, is one step in this 
direction. As Slocum (2004:422) argues: "society is formed by what is speakable, which limits the possible".

Looking beyond the practice of behaviour change, Shove (2010, p. 1278) describes social change in terms of "societal innovation" where the "contemporary rules of the game are eroded" and "in which the status quo is called into question". This requires more effective processes for understanding what those 'rules of the game' are, and legitimately questioning and challenging the 'status quo'. For governments, this necessitates an acceptance that changes to the way we live are required for a more sustainable future and that governments must play a key role in leading and shaping this change. Governments are actively engaged in reinforcing or redefining normal everyday practices by providing physical infrastructure (roads, electricity systems, water supplies), and planning towns, parks and communities, in ways which uphold or challenge the status quo. Adopting a social practice ontology - that is an understanding that the world is populated by social practices and their interconnected elements-requires a far greater consideration of the roles and responsibilities of 'nonbehavioural' departments and professions (such as planning and engineering), in transformative social change.

The scale and level of co-ordination required to respond to the challenges that will emerge from this type of political framing are complex and varied, and requires further reflection and research beyond the scope of this paper. Government and non-government agencies involved in developing and implementing environmental policy and change programs will be required to co-ordinate their approaches across traditional silos (Strengers \& Maller 2011). This means stepping outside the traditional boundaries around what is the subject of change (from ten easy actions or social practices) and who is able to influence it (housing designers, builders, appliance manufacturers, advertisers, electricity providers etc.). Further, it means thinking beyond the scope of the resources we seek to reduce (energy, water, waste) and about the meanings, materials and skills that constitute the practices that use or produce these resources. In this context, thinking differently about how to clean the body, laundry or clothes without energy, water and waste might be more important than focusing on switching to cold water in the laundry.

\section{Conclusion}


This paper has characterised the discourse of Going Green as the pervasive political preoccupation with targeting individual behaviour change and techno-efficiency measures. The dominance, persistence and limitations of the Going Green discourse has been illustrated through the emergence of a range of behaviour change programs and DIY campaigns aimed at encouraging individuals to adopt a number of small and big green actions. Using the example of the ACF GreenHome program, we have demonstrated how this discourse narrowly frames the scope of potential change around a set of actions, whilst ignoring the vast majority of consumption implicated in normal everyday practices.

We have provided evidence from an Australian context which contributes to a growing body of international literature which challenges behaviour change approaches and argues the value of exploring an alternative approach drawing on social practice theories to reframe consumption as a by-product of taken for granted practices. We showed how many daily practices, such as heating cooling, bathing and laundering are largely overlooked in the Going Green discourse, and how they can become more resource-intensive. We warn that changing understandings of normal practice can counteract the consumption reductions achieved through the uptake of a small range of 'green actions' advocated by environmental behaviour change programs. While our primary focus has been to highlight the limitations of the Going Green discourse by providing evidence on what it ignores and leaves unchallenged, we have also aimed to reinforce the value and need for an alternative ontological framing of social change, and the role of government in adopting this theoretical position.

Reframing the discourse of Going Green to one focused on transforming social practices will require strong leadership, co-ordinated support from government agencies and a willingness to confront the many challenges involved in shifting and transforming everyday practices. There are opportunities for behaviour change practitioners to refocus their role on understanding and changing practices rather than targeting individuals. In this way they can act as co-ordinating and strategic agents or intermediaries between households and communities and the challenges they face in living more sustainably. Rather than dismissing policies, regulations and infrastructures involving urban form, housing, transport and infrastructure provision as 'external factors' separate from behaviour, practice theories accord them integral status in the constitution of social order and change. This represents a broader and more challenging agenda for practitioners and governments. We conclude by reiterating that the answer to the world's environmental problems does not necessarily lie in making 'the 
environment' part of our individual decision-making processes, but potentially rests in addressing the elements mutually binding practices together, and the ways they are enacted and reproduced in everyday life. Understanding these interactions is a necessary step to more effectively move beyond the 'behavioural space' reserved for those attempting to achieve farreaching social change. 


\section{References}

ACF 2004, GreenHome, Australian Conservation Foundation (ACF), viewed 16 December 2011, $<$ http://www2.acfonline.org.au/>.

---- 2006, The GreenHome guide: Victorian edition, Australian Conservation Foundation (ACF), Melbourne, VIC.

---- 2009, GreenHome Program: A Study of ACFs GreenHome Program and the contributions the program has made to sustainability practice change across regional Victoria, Australian Conservation Foundation (ACF), Melbourne, Australia.

Ashenburg, K 2007, Clean: an Unsanitised History of Washing, Profile Books Ltd, London [UK].

Barr, S, Shaw, G \& Coles, T 2011, 'Sustainable lifestyles: sites, practices, and policy', Environment and Planning A, vol. 43, no. 12, pp. 3011-29.

Burgess, J, Bedford, T, Hobson, K, Davies, G \& Harrison, C 2003, '(Un)sustainable consumption', in F Berkhout, M Leach \& I Scoones (eds), Negotiating Environmental Change: New Persepectives from Social Science, Edward Elgar, Cheltenham, UK, pp. 261-92.

Christensen, T, Godskesen, M, Gram-Hanssen, K, Quitzau, M-B \& Røpke, I 2007, 'Greening the Danes? Experience with consumption and environment policies', Journal of Consumer Policy, vol. 30, no. 2, pp. 91-116.

Christoff, P 1996, 'Ecological Modernisation, Ecological Modernities ', Environmental Politics, vol. 5, pp. 476-500.

CVGA 2008, How we ran a behaviour change pilot program and the lessons we learnt: Telling the performance story of Castlemaine 500, Central Victorian Greenhouse Alliance (CVGA), Castlemaine, Australia.

Davidson, G 2008, 'Down the gurgler: historical influences on Australian domestic water consumption', in P Troy (ed.), Troubled Waters: Confronting the Water Crisis in Australia's Cities, ANU E Press, Canberra, Australia, pp. 37-65.

DEWHA 2008, Energy Use in the Australian Residential Sector 1986-2020, Australian Government: Department of the Environment, Water, Heritage and the Arts (DEWHA), Canberra, Australia.

EST 2007, The ampere strikes back: How consumer electronics are taking over the world, Energy Savings Trust (EST), London, UK.

Everts, J, Lahr-Kurten \& Watson, M 2011, 'Practice Matters! Geographical inquiry and theories of practice', Erdkunde, vol. 65, no. 4, pp. 323-34.

Giddens, A 1984, The Constitution of Society: Outline of the Theory of Structuration, Polity Press, Cambridge [UK].

Goldsmith, M \& Villadsen, S (eds) 1986, Urban Political Theory and the Management of Fiscal Stress, Gower Publishing Company, UK.

Gram-Hanssen, K 2008, 'Consuming technologies - developing routines', Journal of Cleaner Production, vol. 16, pp. 1181-9.

---- 2009, 'Standby consumption in households analyzed with a practice theory approach', Research and Analysis, vol. 14, no. 1, pp. 150-65.

---- 2011, 'Understanding change and continuity in residential energy consumption', Journal of Consumer Culture, vol. 11, no. 1, pp. 61-78.

Ha, T 2007, Greeniology: how to live well, be green and make a difference, Melbourne University Press, Carlton, Victoria.

Hajer, MA 1995, The Politics of Environmental Discourse: Ecological Modernisation and the Policy Process Oxford University Press.

Halkier, B, Katz-Gerro, T \& Martens, L 2011, 'Applying practice theory to the study of consumption: Theoretical and methodological considerations', Journal of Consumer Culture, vol. 11, no. 1, pp. 3-13. 
Hargreaves, T 2011, 'Practice-ing behaviour change: Applying social practice theory to proenvironmental behaviour change', Journal of Consumer Culture, vol. 11, no. 1, pp. 79-99.

Hawkins, G \& Race, K 2011, 'Bottle water practices: reconfiguring drinking in Bangkok households', in R Lane \& A Gorman-Murray (eds), Material geographies of household sustainability, Ashgate, Farnham, UK, pp. 113-24.

HIA 2009, Welcome to HIA GreenSmart, viewed 10 July 2009, <http://hia.com.au/hia/channel/Builder/region/National/classification/Greensmart.aspx>.

Hinchliffe, S 1996, 'Helping the earth begins at home: the social construction of socio-environmental responsibilities', Global Environmental Change, vol. 6, no. 1, pp. 53-62.

Hobson, K 2002, 'Competing Discourses of Sustainable Consumption: Does the 'Rationalization of Lifestyles' Make Sense? ', Environmental Politics, vol. 11, no. 2, pp. 95-120.

Hobson, K 2006, 'Bins, bulbs, and shower timers: on the "techno-ethics' of sustainable living', Ethics, Place and Environment, vol. 9, pp. 317-36.

Hodson, M \& Marvin, S 2010, 'Can cities shape socio-technical transitions and how would we know if they were?', Research Policy, vol. 39, pp. 477-85.

Hopwood, B, Mellor, M \& O’Brien, G 2005, 'Sustainable Development: Mapping Different Approaches ', Sustainable Development, vol. 13, pp. 38-52.

IPCC 2007, Climate change 2007: synthesis report. Summary for policymakers, International Panel on Climate Change (IPCC), Valencia [Spain].

Jackson, T 2005, Motivating Sustainable Consumption: a Review of Evidence on Consumer Behaviour and Behavioural Change, Centre for Environmental Strategy, University of Surrey, a report to the Sustainable Development Research Network, Surrey, UK.

Jackson, T (ed.) 2006, The Earthscan Reader in Sustainable Consumption, Earthscan, London UK.

Loux, R 2008, Easy green living: the ultimate guide to simple, eco-friendly choices for you and your home, Rodale Inc., New York, USA.

Luke, TW 2005, 'Neither Sustainable nor Development: Reconsidering Sustainability in Development', Sustainable Development, vol. 13, pp. 228-38.

Macnaghten, P 2003, 'Embodying the environment in everyday life practices', The Sociological Review, vol. 51, no. 1, pp. 63-84.

Maller, C, Horne, R \& Dalton, T 2011, 'Green rennovations: intersections of daily routines and housing aspirations and narratives of environmental sustainability', Housing, Theory and Society.

Maniates, M 2002, 'Individualisation: plant a tree, buy a bike, save the world? ', in T Princen, M Maniates \& K Conca (eds), Confronting consumption, MIT Press Cambridge.

Marres, N 2011, 'The costs of public involvement: everyday devices of carbon accounting and the materialization of participation', Economy and Society, vol. 40, no. 4, pp. 510-33.

Mol, A 1999, 'Ontological politics: A word and some questions', in J Law \& J Hassard (eds), Actor Network Theory and After, Blackwell and the Sociological Review, Oxford and Keele, pp. 7489.

Moloney, S, Horne, RE \& Fien, J 2010, 'Transitioning to Low Carbon Communities - From Behaviour Change to Systemic Change: Lessons from Australia', Energy Policy, vol. 38, no. 12, pp. 761423.

OECD 2002, Towards Sustainable Household Consumption? Trends and Policies in OECD Countries, Organisation of Economic Co-operation and Development (OECD), France.

Pantzar, M \& Shove, E 2010, 'Understanding innovation in practice: a discussion of the production and reproduction of Nordic Walking', Technology Analysis \& Strategic Management, vol. 22, no. 4, pp. 447-61.

Reckwitz, A 2002a, 'The status of the 'material' in theories of culture. From 'social structure' to 'artefacts", Journal for the Theory of Social Behaviour, vol. 32, no. 2, pp. 195-217.

--- 2002b, 'Toward a theory of social practices: a development in culturalist theorizing', Journal of Social Theory, vol. 5, no. 2, pp. 243-63. 
Rogers, E \& Kostigen, T, M 2007, The green book: the everyday guide to saving the planet one step at a time, Three Rivers Press, New York, USA.

Røpke, I 2009, 'Theories of practice - New inspiration for ecological economic studies of consumption', Ecological Economics, vol. 68, pp. 2490-7.

Røpke, I, Haunstrup Christensen, T \& Ole Jensen, J 2010, 'Information and communication technologies - A new round of household electrification', Energy Policy, vol. 38, no. 4, pp. 1764-73.

Schatzki, TR 1997, 'Practices and actions: a Wittgensteinian critique of Bourdieu and Giddens', Philosophy of the Social Sciences, vol. 27, no. 3, pp. 283-308.

---- 2002, The Site of the Social: a Philosophical Account of the Constitution of Social Life and Change, The Pennsylvania State University Press, Pennsylvania, USA.

Shipworth, M 2000, Motivating Home Energy Action: a Handbook of What Works, Australian Greenhouse Office, Canberra, Australia.

Shove 2010, 'Beyond the ABC: climate change policy and theories of social change', Environment and Planning A, vol. 42, pp. 1273-85.

---- 2011, 'Commentary: On the different between chalk and cheese - a response to Whitmarsh et al's comments on "Beyond the ABC: climate change policy and theories of social change"', Environment and Planning A, vol. 43, pp. 262-4.

Shove, E 1997, 'Revealing the invisible: sociology, energy and the environment', in M Redclift \& G Woodgate (eds), The International Handbook of Environmental Sociology, Edward Elgar Publishing, Cheltenham, UK, pp. 271-3.

---- 2003, Comfort, Cleanliness and Convenience: the Social Organisation of Normality, Berg Publishers, Oxford, UK.

---- 2010, 'Social Theory and Climate Change: Questions Often, Sometimes and Not Yet Asked', Theory, Culture \& Society, vol. 27, no. 2-3, pp. 277-88.

Shove, E \& Pantzar, M 2005, 'Consumers, producers and practices: understanding the invention and reinvention of Nordic walking', Journal of Consumer Culture, vol. 5, no. 1, pp. 43-64.

Shove, E \& Walker, G 2010, 'Governing transitions in the sustainability of everyday life', Research Policy, vol. 39, pp. 471-6.

Slocum, R 2004, 'Polar bears and energy-efficient lightbulbs: strategies to bring climate change home', Environment and Planning D: Society and Space, vol. 22, no. 3, pp. 413-38.

Southerton, D, A, M \& Evan, D 2011, International Review of Behaviour Change Initiatives: Climate Change Behaviours Research Programme, Scottish Government Social Research.

Spaargaren, G 2011, 'Theories of practices: Agency, technology, and culture: Exploring the relevance of practice theories for the governance of sustainable consumption practices in the new world-order', Global Environmental Change, vol. 21, no. 3, pp. 813-22.

Spaargaren, G \& Oosterveer, P 2010, 'Citizen-consumers as agents of change in globalizing modernity: The case of sustinable consumption', Sustainability, vol. 2, pp. 1887-908.

Strengers, Y 2009, 'Bridging the divide between resource management and everyday life: smart metering, comfort and cleanliness', PhD thesis, RMIT University.

---- 2011, 'Negotiating everyday life: the role of energy and water consumption feedback', Journal of Consumer Culture, vol. 11, no. 19, pp. 319-38.

---- 2012, 'Peak electricity demand and social practice theories: Reframing the role of change agents in the energy sector', Energy Policy, vol. 44, pp. 226-34.

Strengers, Y \& Maller, C 2011, 'Integrating health, housing and energy policies: the social practices of cooling', Building Research \& Information, vol. 39, no. 2, pp. 154-68.

SV 2009a, Green Light Report Sustainability Victoria (SV), Melbourne, Australia.

---- 2009b, You have the power. Save energy., Sustainability Victoria, viewed 12 June 2009, $<$ http://www.saveenergy.vic.gov.au/>.

Thaler, RH \& Sunstein, CT 2008, Nudge: Improving decisions about health, wealth, and happiness, Yale University Press, New Haven, UK. 
UrbanTrans 2008, Stocktake and Analysis of Household Behaviour Change Programs in Victoria Department of Sustainability and Environment (DSE), Melbourne, Australia.

Warde, A 2005, 'Consumption and theories of practice', Journal of Consumer Culture, vol. 5, no. 2, pp. 131-53. 
Table 1: Examples of small green actions

Using a bucket to collect water in the shower and using the water on the garden

Turning off appliances at the powerpoint (turning off standby power)

Changing to energy-efficient light bulbs

Changing to a water-efficient showerhead

Turning off the tap when brushing teeth

Composting food waste

Using a four minute shower timer in the shower

Not turning taps on 'full blast'

Turning off lights when not in use

Hanging laundry on the clothes line rather than using the clothes dryer

Turning the heating/cooling thermostat up or down

Put a jumper on instead of the heater

Table 2: Examples of 'big ticket' green actions

Install a greywater system

Install a water tank

Install solar photovoltaic panels

Purchase front-loading washing machine

Purchase energy-efficient appliances such as fridges, televisions, dishwashers, heaters and air-conditioners

Upgrade or expand insulation

Renovate house to incorporate sustainability features 